\title{
A BRIEF REVIEW ON THE ADVANTAGES, HINDRANCES AND ECONOMIC FEASIBILITY OF STIRLING ENGINES AS A DISTRIBUTED GENERATION SOURCE AND COGENERATION TECHNOLOGY
}

\author{
M. A. Delgado Filho, \\ N. M. F. T. S. Araújo, \\ F. P. Maia, \\ and G. I. Medina Tapia \\ Universidade Federal do Rio Grande do Norte \\ Departamento de Engenharia Mecânica \\ Bairro Lagoa Nova \\ Av. Senador Salgado Filho, S/N. CP 1524 \\ Campus Universitário \\ CEP 59072-970, Natal, RN, Brasil \\ marcdelf6@gmail.com \\ ABSTRACT \\ The present paper aims to provide a brief review of the potentiality and \\ economic feasibility of the Stirling engine as a distributed generation source \\ and cogeneration technology. Another objective was the determination of \\ hindrances which may be preventing the feasibility of the Stirling \\ technology. With these intentions, a research based on a combination of \\ preselected keywords was performed at the Metasearch of CAPES (Brazil's \\ Higher Education Coordination of Personnel Perfecting). No filters in \\ relation to the research period or to particular geographical regions were \\ employed, thus publications until 2017's middle were included and the \\ research was conducted on a global level. Next, the selection of papers \\ which contained some of the keywords was made, consisting initially of the \\ read of the publications' abstracts. The remaining ones were then further \\ explored and had their relevant information incorporated, according to the \\ scope of this work. It is worth mentioning that other accredited sources \\ which dealt with important aspects of the topic were also included. \\ Furthermore, a table containing some examples of products concerning the \\ application of the Stirling engine as a distributed generation and \\ cogeneration technology is presented. Ultimately, it is concluded that the \\ Stirling technology, despite its advantages and suitability regarding the \\ proposed applications, is not yet commercially feasible, having currently \\ only a minor presence in the market. This scenario can be attributed to the \\ need for further research and technical development as well as cost \\ Received: April 14, 2018 \\ reduction. \\ Revised: May 11, 2018 \\ Accepted: May 31, 2018 \\ Keywords: stirling engines, distributed generation, cogeneration, brief \\ review
}

\section{NOMENCLATURE}

Q heat transfered, W

$\mathrm{T}$ temperature, $\mathrm{K}$

\section{Subscripts}

$\begin{array}{ll}\text { H } & \text { hot reservoir } \\ \text { IN } & \text { gain by the working fluid } \\ \text { L } & \text { cold reservoir } \\ \text { OUT } & \text { loss by the working fluid } \\ \text { R,IN } & \text { gain from the regenerator } \\ \text { R,OUT } & \text { loss to the regenerator }\end{array}$

\section{INTRODUCTION}

Electrical power is an indispensable resource to modern society, especially regarding economic activities, human comfort and life quality as well. However, energy consumption tends to increase substantially in the next decades, more precisely in about 48\% from 2012 until 2040 (Fig. 1a), together with the usage of all fossil fuel types, which should be responsible for $78 \%$ of all generated power by the end of this same period (Fig. 1b) (www.eia.gov, February, 16, 2017).

The increasing fossil fuel usage contributes to the aggravation of environmental problems like acid rain and eutrophication (Caetano et al., 2017). In this context, the raise in energy demand is inconsistent with concerns regarding climate changes (Warner and Jones, 2017) and it may, given the reduced energy availability, prevent tendencies of economic growth experienced in the past (Murphy and Hall, 2011). At the same time, more than one billion people still do not have access to electrical power, even with all electricity generation increment (openknowledge.worldbank.org, April, 24, 2017).

This situation calls for the adoption of more efficient and clean ways of energy production, like cogeneration of heat and power (CHP) and trigeneration of cooling, heating and power (CCHP).

In case of isolated areas, distant from consumption centers, the most appropriate and economical way of meeting the electricity demand is with Distributed Generation (DG) since, as pointed by Pepermans et al. (2005), it cuts down distribution and transmission costs, being more versatile, reliable 
and prone to the incorporation of renewable energy sources.

To illustrate this, about 5\% of all energy produced is made unavailable in the United States (US) due to transmission and distribution losses, while the associated costs of these two operations add up to $70 \%$ of energy generation costs (Fig. 2) (www.eia.gov, February, 14, 2017). Besides that, according to ANEEL (National Agency of Electrical Energy), GD is able to reduce grid loading and environmental impacts, contributing to the diversification of the energetic matrix as well (www.aneel.gov.br, February, 18, 2017).

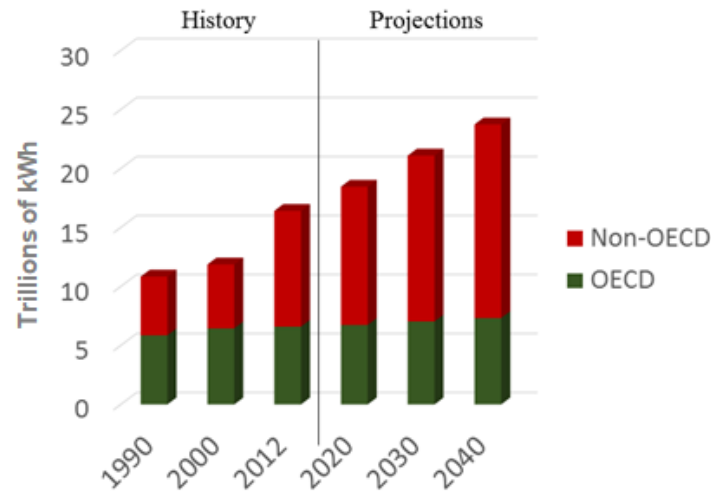

(a)

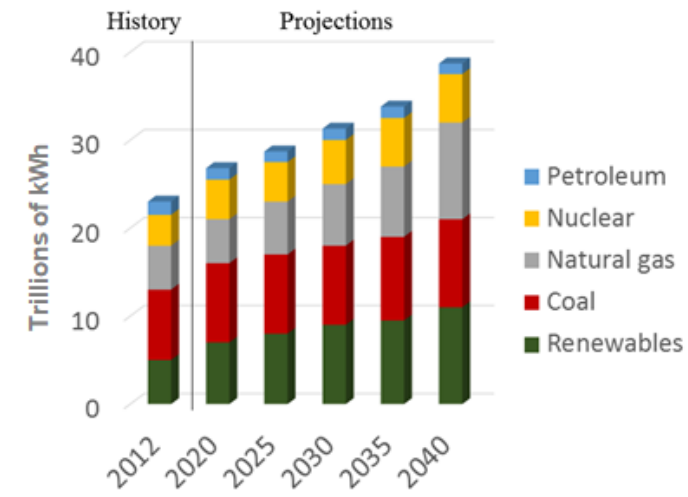

(b)

Figure 1. a) Projections for the global primary energy consumption for members and not members of the Organization for Economic Cooperation and Development (OECD) and b) World net electricity generation by energy source (International Energy Outlook, 2016) (Adapted).

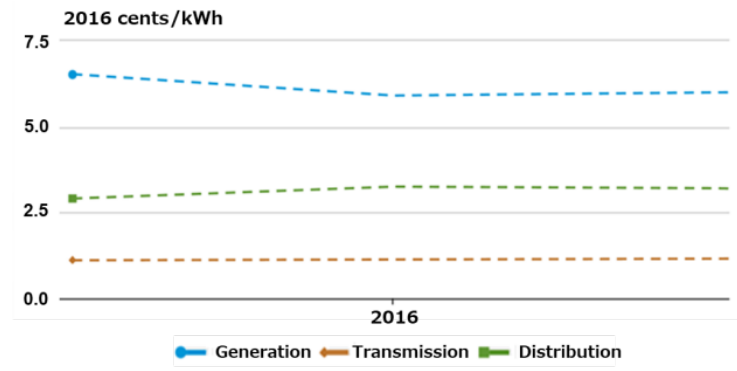

Figure 2. Electricity generation, transmission and distribution costs in the United States from 2015 to 2017 in US cents per kWh (www.eia.gov, February, 14, 2017) (Adapted).

The Stirling technology in this context poses as a promising DG technology, having many conveniences. Among them it is possible to point out a high theoretical efficiency, equivalent to the Carnot one, and the capability of using any source of energy as fuel, which can be of low cost or even cost free. Apart from that, there is also the aptitude of being less pollutant than conventional engines. (Timoumi et al., 2008).

In fact, the new development of the Stirling technology was mainly motivated by the recent interest in DG, being one of its most researched applications, with another substantial motivator being its possibility to be used in cogeneration systems, proportioning better energy usage and power saving.

The objective of this work was therefore to provide a brief review of the advantages, limitations and potentialities of the Stirling Engine (SE) regarding its use both as distributed generation and cogeneration technology, and also to report the main hindrances to its economic feasibility.

Ultimately, it should be noted that due to some imprecision regarding the definition of DG (ElKhattam and Salama, 2004) it is important to explicit the one adopted in this paper. Thus, the definition used here is of a small scale, close to the final costumer generation, that has no connection to the main electrical grid. This definition is similar to the proposed by Dondi et al. (2002).

\section{THEORY}

Before proceeding with this review, a brief explanation of what would be a SE and how it works is considered.

Stirling engines are external combustion engines which operate according to an equally named cycle, where the working fluid stays permanently confined to the system. In order to make the study of its thermodynamic cycle simpler, given its complexity, the real Stirling cycle is approximated to an idealized one, as exposed by Fig. 3a. According to this approach, the cycle would be composed respectively by an isothermal expansion (1-2), an isochoric cooling (2-3), an isothermal compression (3-4) and an isochoric heating (4-1). It is worth mentioning that both isothermal processes involve heat gain $\left(\mathrm{Q}_{\mathrm{IN}}\right)$ or loss (QouT) by the working fluid from and to the hot and cold reservoirs respectively, while the isovolumetric processes deal with heat exchange between the working fluid and the regenerator $\left(Q_{R, I N}\right.$ and $\left.\mathrm{Q}_{\mathrm{R}, \mathrm{OUT}}\right)$.

The operating process of a SE can be better 
visualized for a hypothetical Stirling model, as depicted by Fig. 3b.

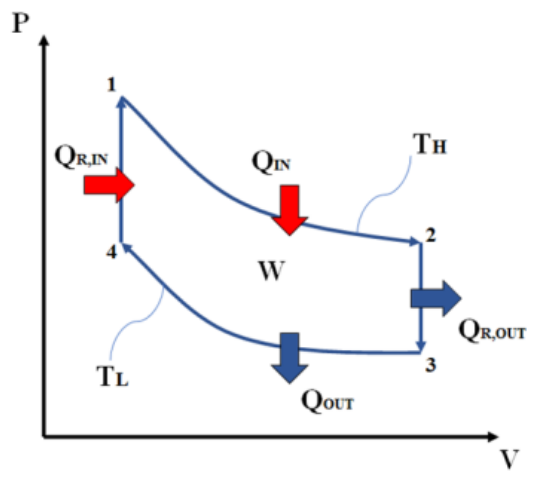

(a)

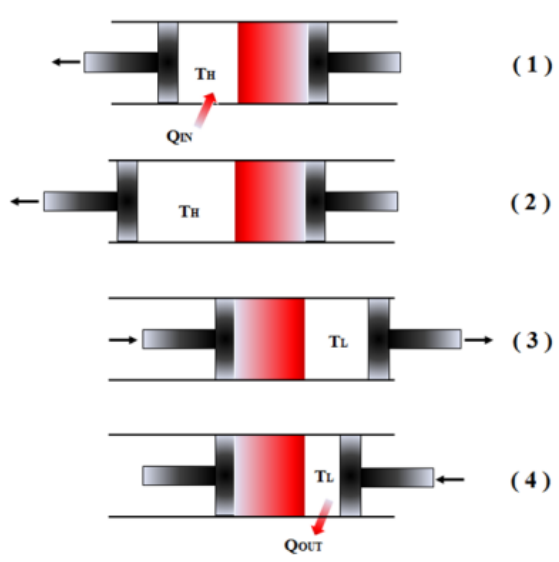

(b)

Figure 3. (a) Ideal Stirling thermodynamic cycle and (b) Main states of Stirling cycle.

As shown, at state 1 , the working fluid is completely contained at one of the two chambers, the left one in this case, being at both high pressure and temperature $\left(\mathrm{T}_{\mathrm{H}}\right)$. Then it receives heat from an external hot source and expands isothermally, producing work as it makes the piston in its chamber move. At state 2, the cycle reaches its maximum volume and both pistons start moving to the left at the same ratio, keeping the system's volume constant. During this stage (2-3), the working fluid is forced through the regenerator, being cooled to the temperature $T_{L}$. When pressure finally drops to its minimum at state 3 , the left piston interrupts its movement and the right one starts to compress isothermally the gas, which exchanges heat with the cold reservoir but remains at the same temperature $\mathrm{T}_{\mathrm{L}}$ (3-4). Finally, in order to complete the cycle, both pistons move to the left at the same ratio, keeping the volume of the system constant and forcing the working fluid through the regenerator again (4-1). Then, the gas receives thermal energy until regaining the temperature $\mathrm{T}_{\mathrm{H}}$ and the cycle is restarted.

\section{RESEARCH METHODOLOGY}

The research was oriented towards answering the three following questions: What are the advantages of the Stirling Engine as a distributed generation source and cogeneration technology? Is it economically feasible? Which would be the reasons preventing its feasibility?

Having these questions as a starting point, publications were found through the Metasearch of CAPES (Brazil's Higher Education Coordination of Personnel Perfecting) using as key-words the combination of the word "Stirling" with the following terms: "engine”, "technology”, “distributed generation" and "cogeneration”. The articles whose titles contained some of these key-words were then selected and had their abstracts read, with the ones that had no relationship with the scope of this research being excluded. Lastly, the remaining publications were read and had their relevant information extracted. It is worth to point out that besides scientific and academic publications some other sources like technical studies were incorporated, given its relevance to the addressed topic and credibility.

Filters regarding the research period were not used, being included publications until 2017's middle in order to incorporate the most recent information to this review. Moreover, the research was conducted on a global level in the attempt to offer a more general and better view about the topic, since, as proposed by Webster and Watson (2002), a complete review should not be restricted only to a specific geographic region.

\section{RESULTS AND DISCUSSION}

\section{Advantages of Stirling Engines as a DG Power Source and Cogeneration Technology}

The SE has several advantages when compared to other DG sources. One of them lies in the fact that the engine operates on a closed cycle, what allows the selection of a working fluid, rather than air, with much desirable properties to maximize engine performance, as chemical inertia and high thermal conductivity. Nevertheless, one of the main advantages of a SE resides in its external combustion, since it occurs in a separate system and thus creates the possibility of utilizing a great variety of fuels to power the engine. (Thombare and Verma, 2008; Çengel and Boles, 2013).

This flexibility is not only restricted to the fuel type but also to its quality, with the possibility of using so called "dirty" combustibles like biomass, firewood and landfill gas without the need of pretreatment or cleaning (www.epri.com, February, 16, 2002). That allows the usage of locally available fuels as, for instance, agricultural waste, what consists in a desirable feature regarding DG.

In fact, virtually any heat source can be employed to run a Stirling motor (Goswami and 
Kreith, 2007). Thus, it is capable of making use of the low grade thermal energy that is widely available in many industrial applications and in nature as well, making it suitable to be used with renewable sources like solar or geothermal energy (Wang et al., 2016).

In this sense, a solar dish Stirling system has a high efficiency, converting nearly $30 \%$ of directnormal incident solar radiation into electricity, even after accounting for parasitic power losses (Mancini et al., 2003). This is superior to most commercially available photovoltaics panels.

Furthermore, Stirling engines are considered simple in construction, safe, and low noise devices (Alfarawi et al., 2017). These aspects added to the fact that they have a thermal to electrical ratio similar to the one demanded by a domestic load make them ideal for residential application (Valenti et al., 2014).

Ultimately, it is important to stress that SEs have high efficiency, meaning they are suitable for cogeneration (Maraver et al., 2013), and, given that the combustion process occurs in a continuous way, and thus tends to be more complete, they produce less emissions compared to conventional engines. (Kong et al., 2004; Moran et al., 2011).

This fact was demonstrated by both computational simulations and experiments. For instance, Kaldehi et al. (2017) reports reductions of at least $40 \%, 50 \%$ and $40 \%$ for CO2, CO and NOx, respectively, as a result of a simulation with an alfa type Stirling. Corroborating with this result, it is concluded that the measured emission levels of a commercial SE model neither presented any health hazards, nor had any negative environmental impacts (www.sgc.se, March, 5, 2004).

\section{Hindrances and Limitations}

Despite all presented advantages and possibilities, SEs have also a couple of limitations and face some hindrances to their feasibility. Figure 4 illustrates how small the diffusion level of the Stirling technology in the market is, being practically inexistent, or less than 3\% to be more specific.

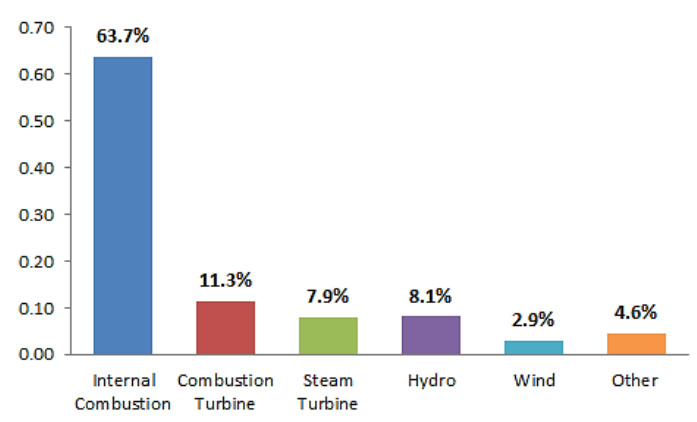

Figure 4. Percent of distributed generation by technology type (Carley, 2009) (Adapted).

One of the main problems, according to several authors (Corria et al., 2006; Alfarawi et al., 2017;
Ferreira et al., 2016) would be the high investment cost of the SE. This can be attributed to the special materials and alloys required to endure the system's operating conditions, which are usually of elevated temperature and pressure (Ferreira et al., 2016). At the same time, there is low market demand for this technology, which is unfamiliar to the general public, and thus cannot benefit from cost reductions proportioned by mass production (www.sgc.se, March, 5, 2004).

Concerning technical aspects, the major issue has been the system durability and reliability in the long run. Some parts subjected to excessive wear, like the shaft seal assembly and piston rings, are expected to have a lifespan of only 5,000 to 10,000 hours, while there is still a need to reduce material stress and corrosion in the high pressure and/or high temperature heater heads. Beyond this, the wear of piston rings generates particles that obstruct the fine meshed heat matrices used in the regenerators, impairing their performance. (www.epri.com, February, 16, 2002).

Corroborating with the former ideas, Mancini et al. (2003) also asserts the need for subsequent technological development, particularly regarding the creation of low cost components which are able to provide reliability to the system. Furthermore, since combustion occurs at atmospheric pressure, Stirling engines have a low power density when compared with Diesel ones (Flannery et al., 2017) and other internal combustion engines in general.

Another relevant technical hurdle is that, although different working fluids may be used to increase considerably the engine performance in relation to the one proportionated by air, like helium (Cheng and Chen, 2017; Abuelyamen et al., 2017), there are problems involving their long-term containment (Minassians and Sanders, 2011). One of the challenges is to design a piston rod seal which is able to keep the working fluid inside the cylinder and prevent lubrication oil from entering it, being, even after several tested solutions, a delicate component of the system (Obernberger et al., 2003). This need for sealing enhancement is also observed by Thombare and Verma (2008), who point out the complexity of projecting a system taking into account thermal, mechanical and fluidic factors.

In relation to solar dish SEs, there are limitations both with low temperature and high temperature ones. The former has low efficiency and specific power in comparison to the latter which, in turn, requires a more complex design and expensive alloys, having thus a higher cost (Sripakagorn and Srikam, 2011).

Moreover, regarding the possibility of using so called dirty fuels to power the SE, like biomass or flue gas, it is important to highlight that ash from these fuels might melt when burned and may cause fouling or slagging issues (Maraver et al., 2013). As a result, the heat transfer in the combustion systems is 
impaired. Corroborating with this idea, Podesser (1999) considers the dust content of the flue gas as the main problem with his biomass powered SE.

Lastly, it is worth mentioning that although being invented in the 19th century, many fundamental design questions still lack a definitive answer, like the way to produce power, whether linear alternator or crankshaft, and system operating temperature and speed, whether high or low (www.epri.com, February, 16, 2002).

\section{Proposed Solutions}

If by one side the potentiality of the Stirling technology makes it a subject of interest, by another some of its current hurdles difficult its commercial implementation. Therefore, the SE remains as an object of research and development in both companies and universities in many countries, having as main enhancement goals efficiency increase, reduction of dead volume and decrease of manufacturing and maintenance costs (Erol et al., 2017). In this sense, some of the proposed solutions found by this research are briefly exposed next.

Smirnov and Golkar (2015), by instance, in face of the actual indetermination of many fundamental design questions, proposed a tradespace exploration framework to assist the project analysis of an SE. This tool allows the determination of parameters of the thermodynamic cycle and engine performance as well, being also able to estimate its capital cost. It still has a tradespace model based in five fundamental design parameters, respectively: engine type, cold and hot source temperature, engine stroke and engine bore. In this way, it is possible to identify the most adequate engine architectures and design parameters to meet a particular application. An interesting result obtained by the authors is the indication that alfa type engines would be more suitable for waste heat recovery, while the beta type would be more adequate for domestic CHP (Smirnov and Golkar, 2015).

Aiming to reduce problems in relation to working fluid leakage, Alberti and Crema (2014), in turn, suggest a double-acting engine configuration, in which the cylinders are opposed as in a boxer engine. With the same objective, Kaldehi et al. (2017) proposes a considerable reduction of operating pressure, being able to achieve in a computational simulation with an alfa SE, at 35 bar, the same power of a real engine at 110 bar, the SOLO V161.

Regarding the selection of the operating temperature of a solar dish Stirling system, Sripakagorn and Srikam (2011) propose the adoption of a moderated working temperature, which would be capable of balancing both cost and efficiency. As a result of their experimental study, it was observed that an increase from 350 to $500{ }^{\circ} \mathrm{C}$ in operating temperature could provide a considerable increment in speed and an increase of about $50 \%$ torque.
Therefore, the operation at moderate temperature could be competitive in relation to the one at high temperature.

\section{General Aspects}

Beyond technical features of the technology itself, there are also economic factors which assume a prominent role in the determination of the Stirling technology feasibility (Ferreira et al., 2017). Together with them, regulatory and political aspects may interfere as well. All of which vary from region to region and may include electrical grid availability, energy price, competitiveness level with other technologies, governmental policies, among others.

By instance, it is concluded that a gas powered cogeneration Stirling system is not competitive in the Swedish market in face of conditions as the low electricity price, the high encompassment level of the domestic electrical grid and limitations in the gas distribution network (www.sgc.se, March, 5, 2004). In contrast, a biomass powered Stirling generator in Brazil is said to be capable of providing energy at a lower cost than the electricity purchased from the grid, thus being widely competitive (Corria et al., 2006).

The deregulation of the energy market is important concerning the feasibility not only of the Stirling technology but of all DG technologies as well (www.sgc.se, March, 5, 2004). In line with this, González-Pino et al. (2015) showed that the regulation framework may play a decisive role in relation to the competitiveness of micro-CHP and particularly the Stirling technology. In their study, it was observed that the high level of feed-in tariffs and support policies in countries like Germany and United Kingdom could provide very attractive payback periods and improvements twice as higher than those in the case of Spain. Therefore, they conclude that the Spanish regulation still has much to improve in order to make micro-CHP, and especially the Stirling technology, competitive.

Moreover, it is worth mentioning that not only macroeconomic and regulatory aspects may influence the implementation of the Stirling technology. Corroborating with this idea, Balcombe et al. (2015) shows that even the variation on demanded energy from one residence to another may constitute a decisive factor in promoting the feasibility of their hybrid photovoltaic CHP Stirling system, concluding that it would be financially beneficial only for domestic consumptions higher than 4,300 kWh/year.

Ultimately, it is important to point out that the economic factors do not simply indicate if a DG technology, is viable or not, but may also establish the optimum way of adjusting it to a given application. As an example of this, Bartela et al. (2017) concludes that, since there is a limited heat demand on the polish domestic market, their Biomass Integrated Gasification Combined Heat and Power 
System (BIGCHP) with a SE is best suited for that market than a conventional cogeneration one, of internal combustion, due its capability of sacrificing efficiency in heat production to increase the efficiency in electricity generation.

\section{Reported Costs}

Despite several authors reporting the high cost of the SE, this is not an absolute consensus, with some authors like Kong et al. (2004) and Kongtragool and Wongwises (2003) stating the opposite. This could be attributed to the great versatility of the Stirling technology, which may incorporate different sizes and configurations, each one with its own associated costs (www.sgc.se, March, 5, 2004). Another worth mentioning fact is that each author utilizes a specific method when performing a cost analysis.

In fact, few cost analysis were found in the researched sources. This may be attributed to the fact that, as pointed out by Ferreira et al. (2017), much of the academic research is mainly focused on the technical aspects of the subject. Therefore, other relevant aspects, like the economic ones, may be cast aside. An example of this is the proposition by Chmielewski et al. (2016) to use a diamond-tungsten material in high temperature heat exchangers what, in spite of improving the system efficiency, ignores the fact that it may increase considerably the cost of the engine and thereby harm its feasibility.

Nevertheless, it was possible to acquire some information of estimated costs, primarily regarding solar dish Stirling systems. Ferreira et al. (2017), while performing a thermal-economic optimization study of a low scale solar powered CHP Stirling system, reports a value of $18,059 €$ as the total capital cost of the plant. The components said to have contributed the most for this amount were the engine bulk, corresponding to $29 \%$ of the total, and the 7.86 m diameter solar dish, contributing with $27 \%$. The proposed plant is to have an annual investment of $1,705 €$ /year, being able to produce, at its optimal condition, $3.61 \mathrm{~kW}$ of electricity and $9.35 \mathrm{~kW}$ of thermal power with a $74.1 \%$ thermal efficiency.

Still regarding a solar dish Stirling, Minassians and Sanders (2011) estimates the cost per watt of a 2 to $3 \mathrm{~kW}$ engine to be of $0.30 \mathrm{USD} / \mathrm{W}$. This value was obtained using basically the mass of the materials employed in the construction of some prototypes and considering economies of scale. However, Mancini et al. (2003) utilizes a more elaborated approach when assessing the cost of this type of system, taking into account other cost related aspects as inflation, taxes, insurance and operating and maintenance costs in order to determine the Levelized Energy Cost (LEC), that is, the ratio between the total annual cost and the total amount of annually produced energy. Thereby, Mancini et al. (2003) estimates, for the actual market scenario, an initial investment ranging from 8,000 to
10,000 USD/kW and an energy cost of $1 \mathrm{USD} / \mathrm{kWh}$. Furthermore, the aforementioned mentioned source points out that these expenses may be reduced through an increase in system reliability, what would lower operating and maintenance costs, and also by a raise in the quantity of manufactured units, which is capable of decreasing its initial costs.

In case of biomass powered Stirling systems, Corria et al. (2006) reports a generation cost of 1,125 to $1,500 \mathrm{USD} / \mathrm{kW}$. Among the expenses which had most influence on these values, it is possible to indicate the cost of the system itself and the ones related to its operation and maintenance. The fuel price, biomass in this case, although not contributing as much as the mentioned variables, is considered as a decisive factor for the system feasibility (Corria et al., 2006).

On the other hand, Kong et al. (2004) when performing an economic feasibility analysis of a CCHP Stirling cogeneration system, highlights that it is related to the avoided cost, annual savings and payback period. The assessed system cost is about 70,000 USD, with the SE being responsible alone for about 42,000 USD from this total. Despite the apparent high cost, the authors determine a period of two to about three years for the investment to be paid back, considering their local economic scenario. Besides that, the plant is reported to provide a $33 \%$ primary energy saving in comparison with a conventional independent system.

\section{Commercial Stirling Engines}

Even with the presented hindrances, many companies have conducted extensive research focused in the Stirling technology. Among them it is possible to mention: General Motors Company (USA), DAF (Netherlands), United Stirling (U.S.A), MAN-MWM Group (Germany), Ford Motors Company (U.S.A.), Siemens (Germany), Cummins (U.S.A.), Perkins (U.K.), and NASA (U.S.A.) (Erol et al., 2017). The intended applications range from the more traditional cogeneration and solar thermal energy conversion to underwater propulsion and space exploration (Sala et al., 2015).

The Swedish company Kockmus, by instance, has manufactured Stirling engines of $75 \mathrm{~kW}$ to be employed as an air-independent propulsion unit (AIP) at submarines. The unit is able to extend in several weeks the submarine operation period when submersed, in comparison with traditional dieselelectric engines and is already operational in the Swedish, Danish and Japanese navies. The NorthAmerican company STM Power Inc., in turn, has produced Stirling based cogeneration systems, claiming of being able of generation $44 \mathrm{~kW}$ of heat and $25 \mathrm{~kW}$ of electricity. Another example of commercial Stirling technology as a cogeneration system is the SOLO V161, built by SOLO Kleinmotoren $\mathrm{GmbH}$, which may also be used to 
generate power from a solar dish configuration (www.sgc.se, March, 5, 2004).

Table 1 presents a set of DG and cogeneration Stirling technology developed by some companies.

\section{CONCLUSIONS}

It is concluded that the Stirling engine is very suitable to be employed both as distributed generation and cogeneration technology, since it is versatile, being able to be employed with practically any energy sources available, efficient and in accordance with current environmental concerns. Moreover, SEs are safe and low noise devices adequate for domestic applications. Faced with all these advantages, it is possible to observe a considerable business interest in relation to the Stirling technology, with several companies attempting to develop products from it.
However, there are some hindrances preventing its massive market entrance. One of them is the high cost of the SE, due to its low production level and the usually expensive materials used in its construction. Other major problems include the lack of reliability and durability of its components, which poses as a considerable hurdle, especially regarding DG applications, and also technical issues as working fluid leakage. Therefore, as a result, the Stirling technology still remains mainly as an object of research and development by companies and the academic community, being not yet feasible for most markets. Lastly, it is important to highlight that besides technical aspects, economic factors and governmental policies may greatly influence the feasibility of the Stirling distributed generation and cogeneration technology, and that these factors must be properly assessed and if one intends to make this technology competitive at a given market.

Table 1. Set of DG and cogeneration Stirling technology, by company, country, model, application and maximum output.

\begin{tabular}{|c|c|c|c|c|}
\hline Company & Country & Model & Application & Maximum output \\
\hline Kockums $^{\text {a }}$ & Sweden & Kockmus Stirling AIP & Submarine propulsion unit & $75 \mathrm{~kW}$ \\
\hline STM Power Inc. & USA & STM 4-120 & Cogeneration & $\begin{array}{l}\text { Heat: } 45 \mathrm{~kW} \\
\text { Power: } 25 \mathrm{~kW}\end{array}$ \\
\hline Stirling Energy Systems ${ }^{\text {b }}$ & USA & $\begin{array}{l}\text { SES Dish-Stirling } \\
\text { Systems }\end{array}$ & $\begin{array}{c}\text { Power production using solar } \\
\text { energy }\end{array}$ & $24.9 \mathrm{~kW}$ \\
\hline Sunpower Inc. & USA & BIOWATTT & Cogeneration & $10 \mathrm{~kW}$ \\
\hline Tessera Solar & USA & Maricopa Solar Plant & $\begin{array}{c}\text { Power production using solar } \\
\text { energy }\end{array}$ & $1.5 \mathrm{MW}$ \\
\hline Stirling Technology Inc. & USA & ST 5 & Water pumping & $3.7 \mathrm{~kW}$ \\
\hline SAIC/STM & USA and China & SunDish & $\begin{array}{c}\text { Power production using solar } \\
\text { energy }\end{array}$ & $22.9 \mathrm{~kW}$ \\
\hline United Stirling, Inc. & $\begin{array}{l}\text { USA and } \\
\text { Sweden }\end{array}$ & V160 D & $\begin{array}{c}\text { Power production using solar } \\
\text { energy }\end{array}$ & $27 \mathrm{~kW}$ \\
\hline Cleanergy & Sweden & SunBox & $\begin{array}{c}\text { Power production using solar } \\
\text { energy }\end{array}$ & $13 \mathrm{~kW}$ \\
\hline SOLO Kleinmotoren GmbH & Germany & SOLO V161 & Cogeneration & $\begin{array}{c}\text { Heat: } 26 \mathrm{~kW} \\
\text { Power: } 9.5 \mathrm{~kW}\end{array}$ \\
\hline VE-Ingenieure & Germany & ST05G & Demonstration & $0.5 \mathrm{~kW}$ \\
\hline $\begin{array}{l}\text { Schlaich Bergermann und } \\
\text { Partner (SBP) }\end{array}$ & $\begin{array}{l}\text { Germany, } \\
\text { Spain and } \\
\text { others }\end{array}$ & EuroDish & $\begin{array}{l}\text { Power production using solar } \\
\text { energy }\end{array}$ & $10 \mathrm{~kW}$ \\
\hline Stirling DK & Denmark & SDK & Power production & $35 \mathrm{~kW}$ \\
\hline Whisper Tech Limited. & New Zealand & WhisperGen & Cogeneration & $\begin{array}{c}\text { Heat: } 6 \mathrm{~kW} \\
\text { Power: } 800 \mathrm{~W}\end{array}$ \\
\hline Sigma Elektroteknisk A.S. ${ }^{c}$ & Norway & PCP 1-130 & Cogeneration & $\begin{array}{c}\text { Heat: } 9 \mathrm{~kW} \\
\text { Power: } 1.5 \mathrm{~kW}\end{array}$ \\
\hline Inspirit Energy Holdings Plc & $\begin{array}{c}\text { United } \\
\text { Kingdom }\end{array}$ & Inspirit Charge & Cogeneration & $\begin{array}{l}\text { Heat: } 15 \mathrm{~kW} \\
\text { Power: } 3 \mathrm{~kW}\end{array}$ \\
\hline $\begin{array}{l}\text { Suction Gas Engine Mfg. } \\
\text { Co., Ltd }\end{array}$ & Japan & $\begin{array}{l}\text { Low temperature } \\
\text { differential engine }\end{array}$ & Power production & $1 \mathrm{~kW}$ \\
\hline
\end{tabular}

Acquired by SAAB

${ }^{\mathrm{b}}$ Closed in 2011

${ }^{\text {c }}$ Current denomination: Merck

\section{ACKNOWLEDGEMENTS}

The authors acknowledge the support provided by the Laboratory of Thermal Systems and Alternative Energies (LSTEA), belonging to the Department of Mechanical Engineering (DEM) of
Federal University of Rio Grande do Norte (UFRN).

\section{REFERENCES}

Abuelyamen, A., Ben-Mansour, R., Abualhamayel, H., and Mokheimer, E. M. A., 2017, 
Parametric Study on Beta-Type Stirling Engine, Energy Conversion and Management, Vol. 145, pp. 53-63.

Alberti, F., and Crema, L., 2014, Design of a new Medium-Temperature Stirling Engine for Distributed Cogeneration Applications, 2013 ISES Solar World Congress, Energy Procedia, Vol. 57, pp. 321-330.

Alfarawi, S., Al-Dadah, R., and Mahmoud, S., 2017, Potentiality of New Miniature-Channels Stirling Regenerator, Energy Conversion and Management, Vol. 133, pp. 264-274.

Balcombe, P., Rigby, D., and Azapagic, A., 2015, Energy Self-Sufficiency, Grid Demand Variability and Consumer Costs: integrating Solar PV, Stirling Engine CHP and Battery Storage, Applied Energy, Vol. 155, pp. 393-408.

Bartela, L., Kotowicz, J., Remiorz, L., ShorekOsikowska, A., and Dubiel, K., 2017, Assessment of the Economic Appropriateness of the Use of Stirling Engine as Additional part of a Cogeneration System based on Biomass Gasification, Renewable Energy, Vol. 112, pp. 425-443.

Caetano, N. S., Mata, T. M., Martins, A. A., and Felgueiras, M. C., 2017, New Trends in Energy Production and Utilization, Energy Procedia, Vol. 107, pp. 7-14.

Carley, S., 2009, Distributed Generation: an Empirical Analysis of Primary Motivators, Energy Policy, Vol. 37, pp. 1648-1659.

Cheng, C. H., and Chen, Y. F., 2017, Numerical Simulation of Thermal and Flow Fields Inside a 1kW Beta-Type Stirling Engine, Applied Thermal Engineering, Vol. 121, pp. 554-561.

Chmielewski, A., Gumiński, R., Mączak, J., Radkowski, S., and Szulim, P., 2016, Aspects of Balanced Development of RES and Distributed Micro-Cogeneration use in Poland: Case Study of a $\mu \mathrm{CHP}$ with Stirling Engine, Renewable and Sustainable Energy Reviews, Vol. 60, pp. 930-952.

Corria, M. E., Cobas, V. M., and Lora, E. S., 2006, Perspectives of Stirling Engines use for Distributed Generation in Brazil, Energy Policy, Vol. 34, pp. 3402-3408.

Çengel, Y. A., and Michael, A. B., 2013, Thermodynamics: an Engineering Approach, 8th Edition, McGraw-Hill.

Dondi, P., Bayoumi, D., Haederli, C., Julian D., and Suter, M., 2002, Network Integration of Distributed Power Generation, Journal of Power Sources, Vol. 106, pp. 1-9.

El-Khattam, W., and Salama, M. M. A., 2004, Distributed Generation Technologies, Definitions and Benefits, Electric Power Systems Research, Vol. 71, pp. 119-128.

Erol, D., Yaman, H., and Doğan, A., 2017, A Review Development of Rhombic Drive Mechanism Used in the Stirling Engines, Renewable and Sustainable Energy Reviews, Vol. 78, pp. 1044-1067.

Ferreira, A. C., Nunes, M. L., Teixeira, J. C. F.,
Martins, L. A. S. B, Teixeira, F. C. F., and Nebra, S. A., 2017, Design of a Solar Dish Stirling Cogeneration System: application of a MultiObjective Optimization Approach, Applied Thermal Engineering, Vol. 123, pp. 646-657.

Ferreira, A. C., Nunes, M. L., Teixeira, J. C. F., Martins, L. A. S. B., and Teixeira, S. F. C. F, 2016, Thermodynamic and Economic Optimization of a Solar-Powered Stirling Engine for MicroCogeneration Purposes, Energy, Vol. 111, pp. 1-17.

Flannery, B., Finckh, O., Berresheim, H., and Monaghan, R. F. D., 2017, Hybrid Stirling EngineAdsorption Chiller for Truck Auxiliary Power Unit Applications, International Journal of Refrigeration, Vol. 76, pp. 356-366.

González-Pino, I., Pérez-Iribarren, E., CamposCelador, A., Las-Heras-Casas, J., and Sala, J. M., 2015, Influence of the Regulation Framework on the Feasibility of a Stirling Engine-Based Residential Micro-CHP Installation, Energy, Vol. 84, pp. 575588.

Goswami, D. Y., and Kreith F., 2007, Handbook of Energy Efficiency and Renewable Energy, CRC Press.

Kaldehi, B. J., Keshavarz, A., Pirooz, A. A. S., Batooei, A., and Ebrahimi, M., 2017, Designing a Micro Stirling Engine for Cleaner Production of Combined Cooling Heating and Power in Residential Sector of Different Climates, Journal of Cleaner Production, Vol. 154, pp. 502-516.

Kong, X. Q., Wang, R. Z., and Huang, X. H., 2004, Energy Efficiency and Economic Feasibility of CCHP Driven by Stirling Engine, Energy Conversion and Management, Vol. 45, pp. 1433-1442.

Kongtragool, B., and Wongwises, S., 2007, Performance of Low-Temperature Differential Stirling Engines, Renewable Energy, Vol. 32, pp. 547-66.

Mancini, T., Heller, P., Butler, B., Osborn, B., Schiel, W., Goldberg, V., Buck, R., Diver, R., Andraka, C., and Moreno, J., 2003, Dish-Stirling Systems: an Overview of Development and Status, Journal of Solar Energy Engineering, Vol. 125, pp. 135-151.

Maraver, D., Sin, A., Royo, J., and Sebastián, F., 2013, Assessment of CCHP Systems Based on Biomass Combustion for Small-Scale Applications Through a Review of the Technology and Analysis of Energy Efficiency Parameters, Applied Energy, Vol. 102, pp. 1303-1313.

Minassians, A. D., and Sanders, S. R., 2011, Stirling Engines for Distributed Low-Cost SolarThermal-Electric Power Generation, Journal of Solar Energy Engineering, Vol. 133, pp. 1-10.

Moran, M. J., Shapiro, H. N., Boettner, D. D., and Bailey, M. B., 2013, Fundamentals of Engineering Thermodynamics, 6th Edition, Wiley.

Murphy, D. J., and Hall, C. A. S., 2011, Adjusting the Economy to the New Energy Realities of the Second Half of the Age of Oil, Ecological 
Modelling, Vol. 223, pp. 67-71.

Obernberger, I., Carlsen, H., and Biedermann, F., 2003, State-of-the-Art and Future Developments Regarding Small-Scale Biomass CHP Systems with a Special Focus on ORC and Stirling Engine Technologies, in: International Nordic Bioenergy Conference.

Pepermans, G., Driesen, J., Haeseldonckx, D., Belmans, R., and D’haeseleer, W., 2005, Distributed Generation: definition, Benefits and Issues, Energy Policy, Vol. 33, pp. 787-798.

Podesser, E., 1999, Electricity Production in Rural Villages with a Biomass Stirling Engine, Renewable Energy, Vol. 16, pp. 1049-1052.

Sala, F., Invernizzi, C., Garcia, D., Gonzalez, M. A., and Prieto, J. I., 2015, Preliminary Design Criteria of Stirling Engines Taking into Account Real Gas Effects, Applied Thermal Engineering, Vol. 89, pp. 978-989.

Smirnov, D., and Golkar, A., 2015, Stirling Engine Systems Tradespace Exploration Framework, Conference on Systems Engineering Research, Procedia Computer Science, Vol. 44, pp. 558-567.

Sripakagorn, A., and Srikam, C., 2011, Design and Performance of a Moderate Temperature Difference Stirling Engine, Renewable Energy, Vol. 36, pp. 1728-1733.

Thombare, D. G., and Verma, S. K., 2008, Technological Development in the Stirling Cycle Engines, Renewable and Sustainable Energy Reviews, Vol. 12, pp. 1-38.

Timoumi, Y., Tliti, I., and Nasrallah, S., 2008, Performance Optimization of Stirling Engines, Renewable Energy, Vol. 33, pp. 2134-2144.

Valenti, G., Silva, P., Fergnani, N., Di Marcoberardino, G., Campanari, and S., Macchi, E., 2014, Experimental and Numerical Study of a MicroCogeneration Stirling Engine for Residential Applications, in 68th Conference of the Italian Thermal Machines Engineering Association, Energy Procedia, Vol. 45, pp. 1235-1244.

Wang, K., Sanders, S. R., Dubey, S., Choo, F. H., and Duan, F., 2016, Stirling Cycle Engines for Recovering Low and Moderate Temperature Heat: a Review, Renewable and Sustainable Energy Reviews, Vol. 62, pp. 89-108.

Warner, K. J., and Jones, G. A., 2017, A Population-Induced Renewable Energy Timeline in Nine World Regions, Energy Policy, Vol. 101, pp. 65-76.

Webster, J., and Watson, R. T., 2002, Analyzing the Past to Prepare for the Future: Writing a Literature Review, MIS Quarterly, Vol. 26, No. 2, pp. 13-23. 